\section{Chromatic changes in paintings of Adriano de Sousa Lopes after the removal of aged varnish}

\author{
Variações cromáticas em pinturas de Adriano \\ de Sousa Lopes após a remoção de verniz oxidado
}

\author{
JOÃO LINHARES ${ }^{1 *}$ \\ LILIANA CARDEIRA ${ }^{2,3}$ \\ ANA BAILÃO ${ }^{2,4}$ (1) \\ RUBEN PASTILHA \\ SÉRGIO NASCIMENTO ${ }^{1}$ \\ 1. Universidade do Minho, \\ Centro de Física, Laboratório \\ de Ciências da Cor, Campus de \\ Gualtar, Gualtar, 4710-057 Braga, \\ Portugal \\ 2. CIEBA, Faculdade de Belas- \\ Artes da Universidade de Lisboa, \\ Largo da Academia Nacional \\ de Belas-Artes, $\mathrm{n}^{\circ} 4,1249-058$ \\ Lisboa, Portugal \\ 3. Laboratório HERCULES, \\ Universidade de Évora, Palácio \\ do Vimioso $\mathrm{n}^{\circ} 8,7000-809$ \\ Évora, Portugal \\ 4. CITAR, Universidade Católica \\ Portuguesa, Rua Diogo Botelho, \\ $\mathrm{n}^{\circ} 1327,4169-005$ Porto, Portugal \\ *jlinhares@fisica.uminho.pt
}

\section{KEYWORDS}

Colours

Varnish layer

Paintings

Hyperspectral imaging

Spectral analysis

Digital removal

\section{PALAVRAS-CHAVE}

Cores

Camada de verniz

Pinturas

Imagiografia hiperespectral Análise espectral

Remoção digital 


\section{Introduction}

With time, the varnish layer that protects and enhances the surface of an artistic painting deteriorates and reduces the visibility of the painting, becoming yellowish with darker spots and unreadable. This yellowing, also referred to as oxidation, is produced by light, contaminants present in the environment and moisture, among others [1, p. 16]. This pathology, in addition to the aforementioned characteristics, leads to the loss of glossiness, brightness of textures [2, p. 170] and, finally, elasticity of the protective layer, making it sometimes brittle [3, p. 82]. Removing the unwanted varnish layer is therefore important as long as some conditions are observed [4], the main purpose of the intervention being to remove the varnish layer without damaging the original painting.

Other methodologies have described the digital restoration of artistic paintings, either based on spectral information [5-6] or colour information with input from spectral data [7-9] or considering only the colour information obtained using traditional digital cameras [10-11]. Nevertheless, the methods described, although more representative of the optical effects in place at the time the light casts on the painting and is reflected and viewed or acquired [12-16], either require the knowledge of the transmittance spectra of the varnish used as a protective layer, or intend to simulate the cleaning and posterior reposition of the varnish layer with the highest possible spectral precision.

The work here presented intends to be a simpler approach to the digital restoration towards a faster and wider usage of the methodology to provide a closer representation of the simulated image without the varnish layer. Collecting information about the spectral influence of the varnish layer
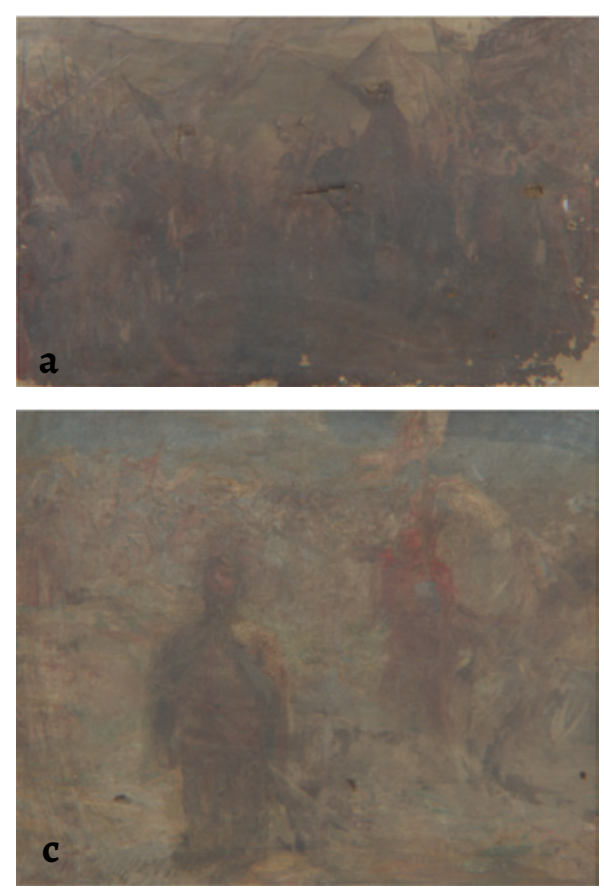

Figure 1. Paintings Cerco de Lisboa, 1384 (painting 1) ( $a$ and $b$ ) and Nuno Álvares em Valverde (painting 2) $(c$ and $d)$, before $(a$ and $c)$ and after $(b$ and $d)$ removing

the protective varnish layer.

will provide a database of its influence that could be used with the reflectance spectra acquired from hyperspectral imaging of the original painting [17-21] which is being widely available, without the need of further chemical or physical interaction with the painting.

The best simulations of the varnish removal were found when using each painting's information of its varnish layer and not the averaged information collected across the two paintings analysed. Nevertheless, both methodologies presented higher errors than the visual threshold for complex images, which seems to indicate that further modelling is required to provide a usable digital restoration.

\section{Methods}

\section{Description of the paintings}

As a case study, two artworks by Adriano de Sousa Lopes (1879-1944) with the title Cerco de Lisboa, 1384 (FBAUL/3560/P), from 1906, and Nuno Álvares em Valverde (FBAUL/3634/P), from 1904, were used and represent the stages of Nuno Álvares Pereira's life. These paintings were made by oil on canvas and measure $54.3 \mathrm{~cm} \times 81.5 \mathrm{~cm}$ and $46 \mathrm{~cm} \times 55 \mathrm{~cm}$, respectively, and were labelled as painting 1 and painting 2 , respectively.

Adriano de Sousa Lopes was a student of the School of Fine Arts (1895-1903), having gone to Paris in 1903 as a legacy Valmor scholar to further his studies at the École des BeauxArts. The paintings are academic works produced in Paris and belong to the painting storage of the Faculty of Fine Arts of the University of Lisbon [22].

Figure 1 represents the paintings used in the analysis described here, before and after the removal of the varnish layer.
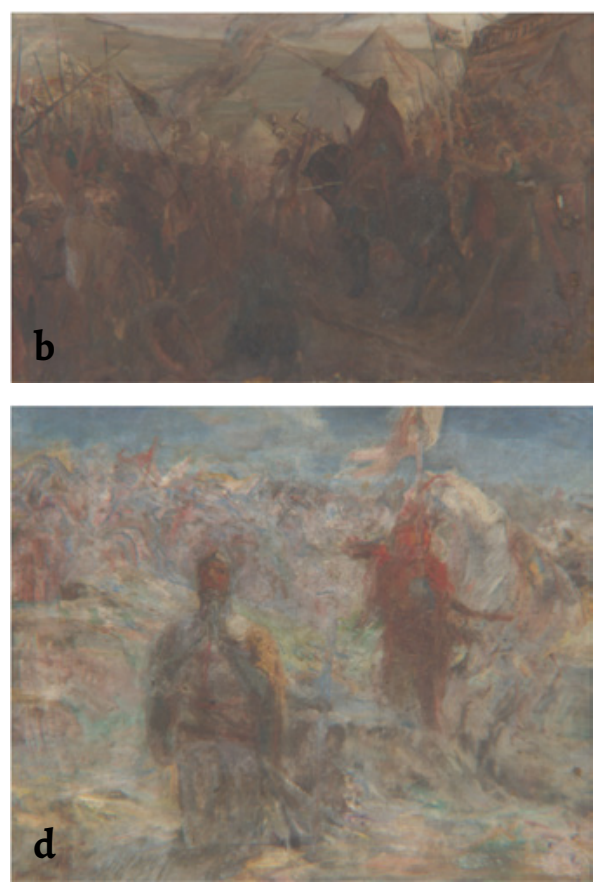


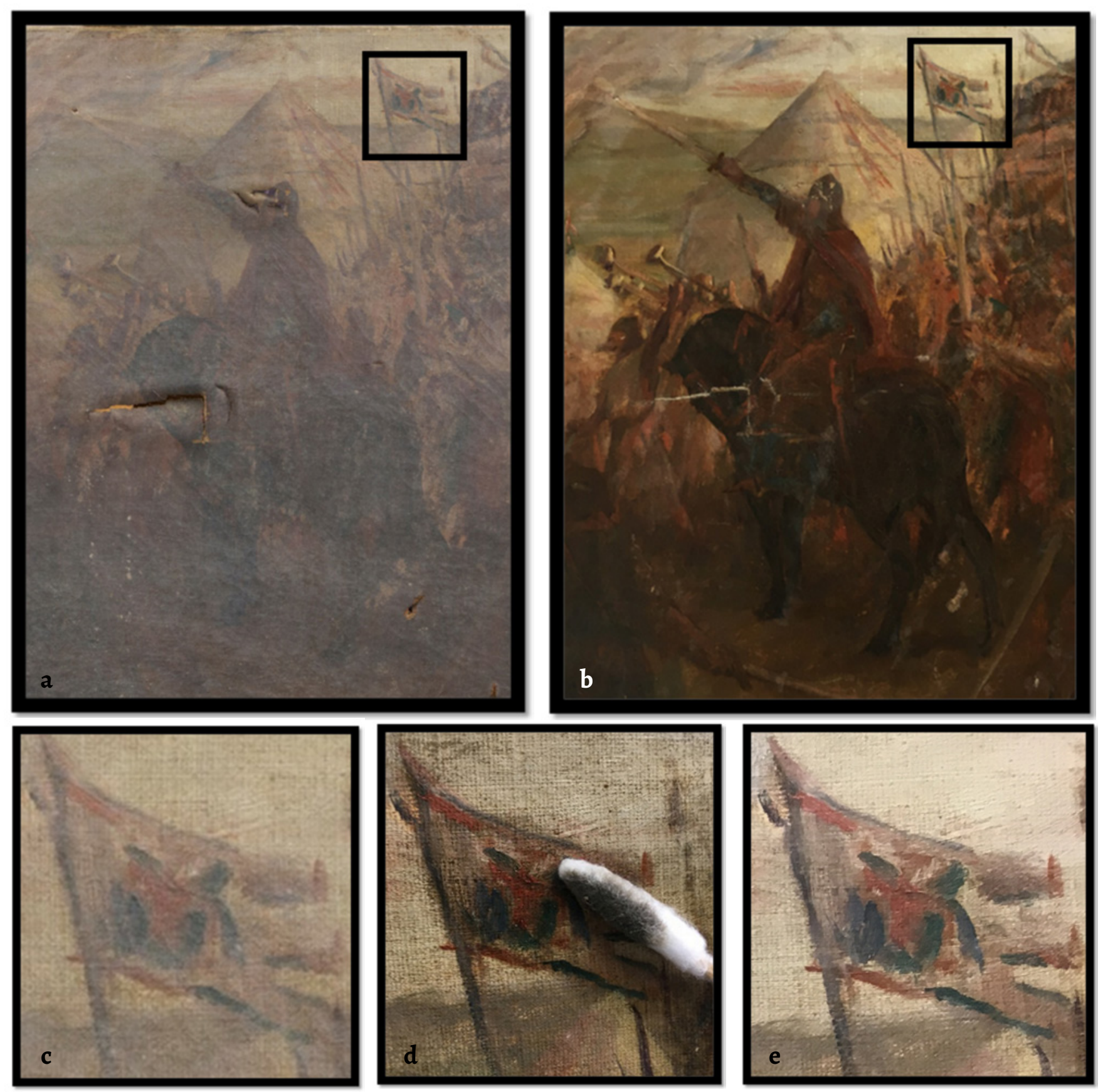

Figure 2. Detail of a cleaning area of painting 1 before ( $a$, with detail in $c)$, during $(d)$ and after cleaning ( $b$ with detail in $e$ ).

\section{Conservation and restoration treatments \\ State of conservation}

Both paintings presented a homogeneous layer of dust and dirt, with special incidence in areas of deformations and tears, both in the front and in the backside. The layers of dirt can be a complex mixture of organic and inorganic materials, which could include particulates and amorphous substances that can differ according to the history of the painting and its environment. Also, the deposits could adhere strongly on the surface and in some instances may even be absorbed into the layer of the coating [23]. There was a marked browning resulted from the aging of the varnish and the deposition of dust and other environmental pollutants. This layer, being the outer layer of the artwork, is also the most exposed to the agents of deterioration. In addition to a darkened structure, it lost flexibility and yellowed, thus presenting changes in optical, physical and chemical properties. As a result, it became more insoluble in the solvents in which it was prepared.

It should also be noted that the application of the varnish was not homogeneous, resulting in accumulation in some areas more than in others, namely in the peripheries as can be seen in Figures 2 and 3. This discrepancy caused differences over time and a distinct yellowing/darkening in the form of spots, in different areas of the painting, a factor that compromised the reading of the pictorial composition. 

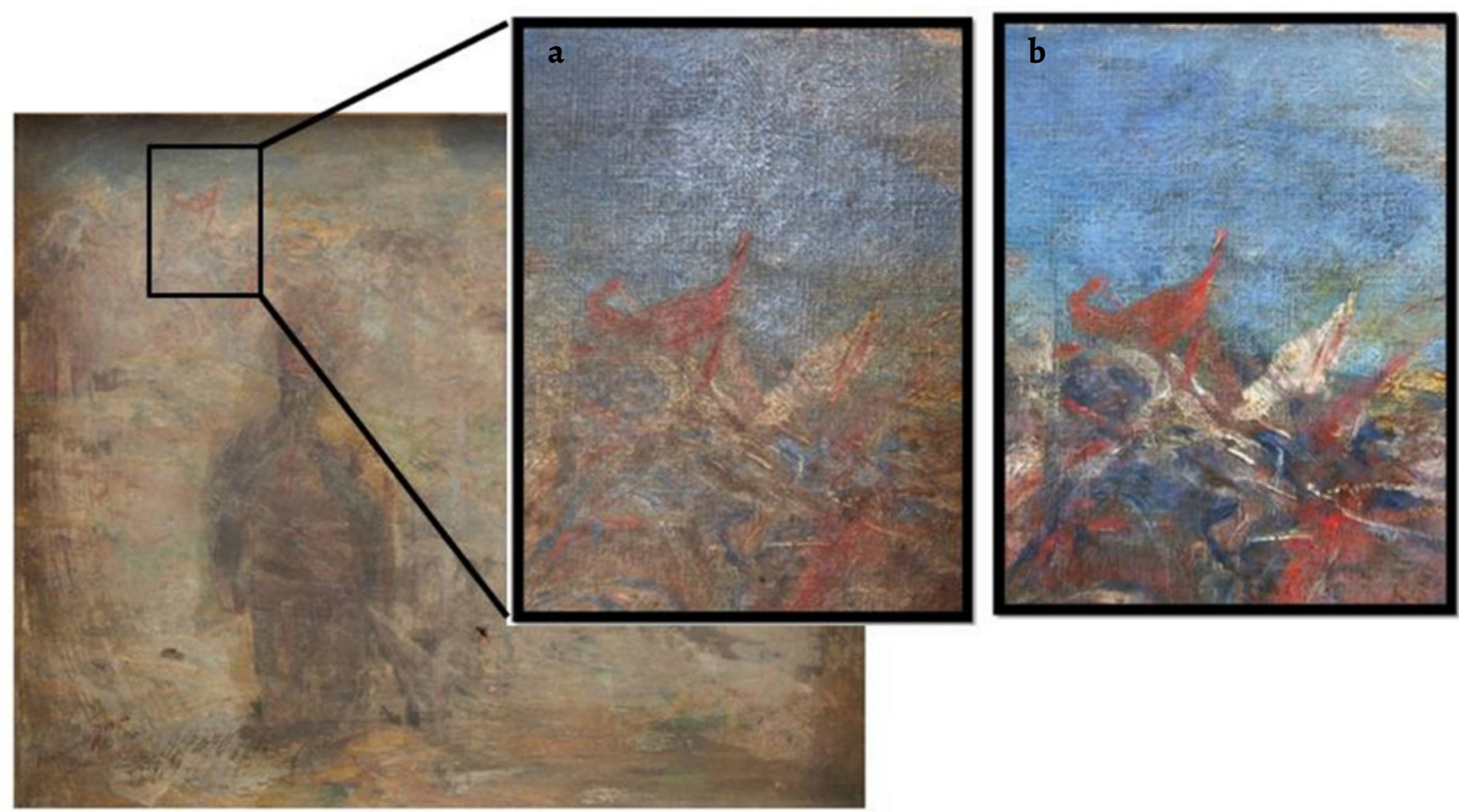

Figure 3. Detail of a cleaning area of painting 2 before (a) and after cleaning (b).

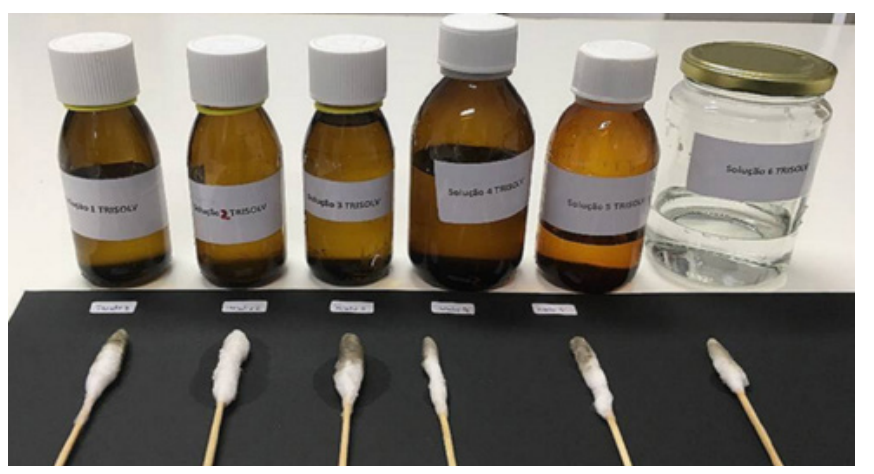

Figure 4. Cleaning tests with 6 TriSolv solutions carried out at painting 1 .

\section{Cleaning}

After assessing the state of conservation of the paintings and its structure, a conservation and restoration intervention methodology was devised and applied to meet the needs of each individual piece, as well as to respect the ethical criteria of Conservation and Restoration [4].

Aiming to remove the oxidized varnish, which no longer assumes the original function - protection and readability [2] -, wet cleaning was carried out. Two cleaning systems were tested: a mixture of nonpolar and polar organic solvents and gelled polar organic solvents.

Several solubility tests were performed for each coloured area. The purpose was to test different solutions with increasing degree of polarity to determine the solubility parameters of the varnish. The TriSolv solubility triangle of the Istituto Superiore per la Conservazione ed il Restauro (ISCR) [24] was used as reference. We chose three solvents: isoctane, ethyl alcohol and acetone, distributed in six possible combinations
(Figure 4). This method was selected considering its low toxicity, an essential aspect to consider the protection of the conservator-restorer and the environment.

As the varnish used by the artist on the paintings was unknown and to ensure the safety and integrity of the paintings, the tests to remove the varnish started with low polarity solutions. It was found that in the case of painting 1 the varnish was only solubilized by the mixture of ethanol (18 $\mathrm{mL})$, isooctane $(40 \mathrm{~mL})$ and acetone $(42 \mathrm{~mL})$ corresponding to the TriSolv 4 solution (Figure 2). The selected solution, according to the data obtained through TriSolv triangle, allows the dissolution of materials based on oil, a natural resin or a synthetic resin.

The set of solutions devised and tested in painting 1 proved to be ineffective for painting 2 mainly for two reasons: the low polarity of the solution and the rapid evaporation of the solvents. From the tested solutions, it was found that more satisfactory results were obtained with acetone. However, even with this solution the results obtained were not considered sufficient. To improve the output, the retention time was increased and acetone (Carbopol Resin + Ethomeen C12) [25] (see Figure 3 and 4) was gelled [25, pp. 62-65], [26]. After the removal of the varnish layer, it was verified that the paint had a darkened layer of dirt, reason for which it was deduced that the work was not varnished after its completion and drying. The time between the drying of the work and the varnishing must have been significant, as the varnish was applied onto a layer of dirt on the painting's surface. This layer of dirt was removed with a solution of demineralized water and one drop of Brij 35 surfactant of neutral pH [25] (see Figure 5). 
Chromatic changes in paintings of Adriano de Sousa Lopes after the removal of aged varnish

Clening tests

Clean tests

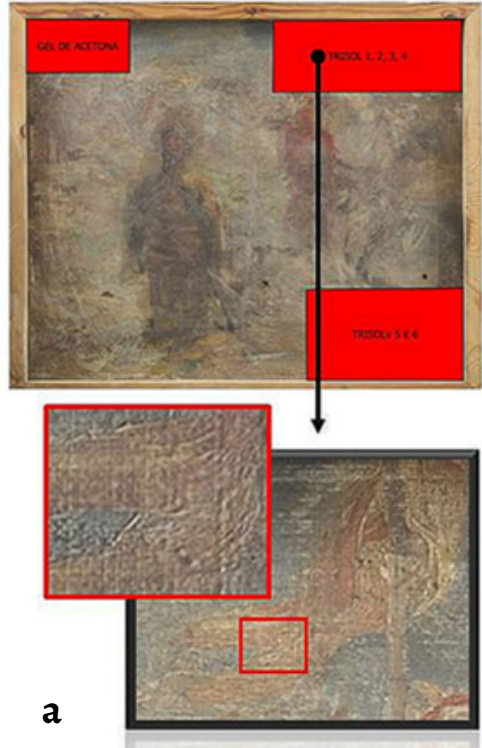

Clening with acetone gel $\square \square \square \square$ Figures and background
Cleaning of dirt

Acetone Solvent

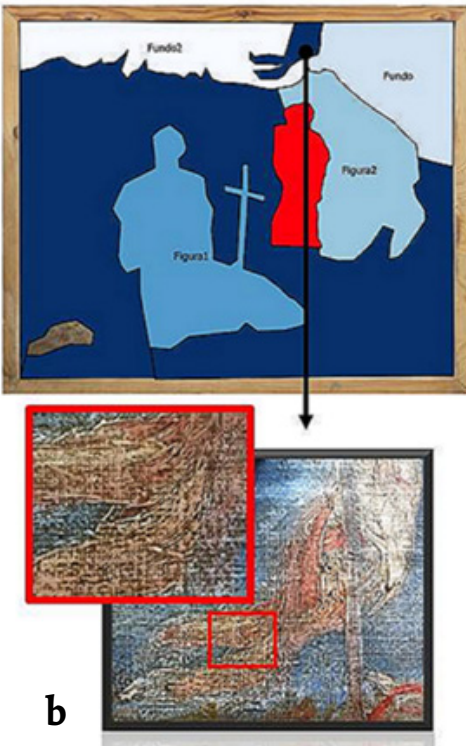

Water + drop of Brij $\otimes 35$

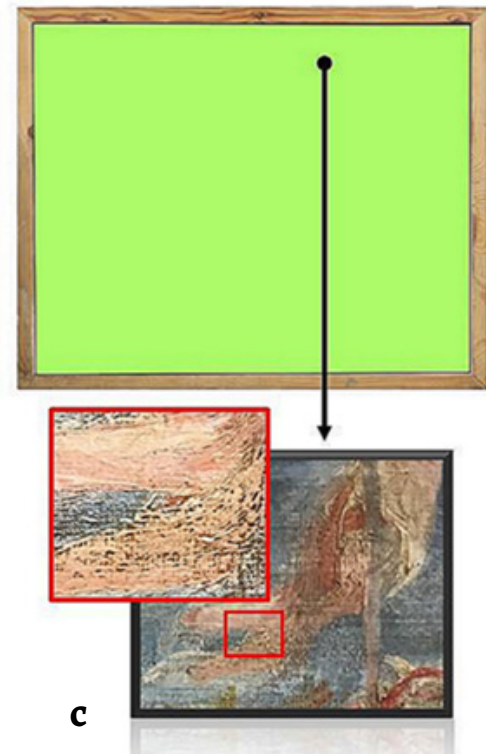

Figure 5. Several stages of cleaning in painting 1 : $a$ ) the cleaning tests; $b$ ) the cleaning with acetone gel; $c$ ) the cleaning of dirt.
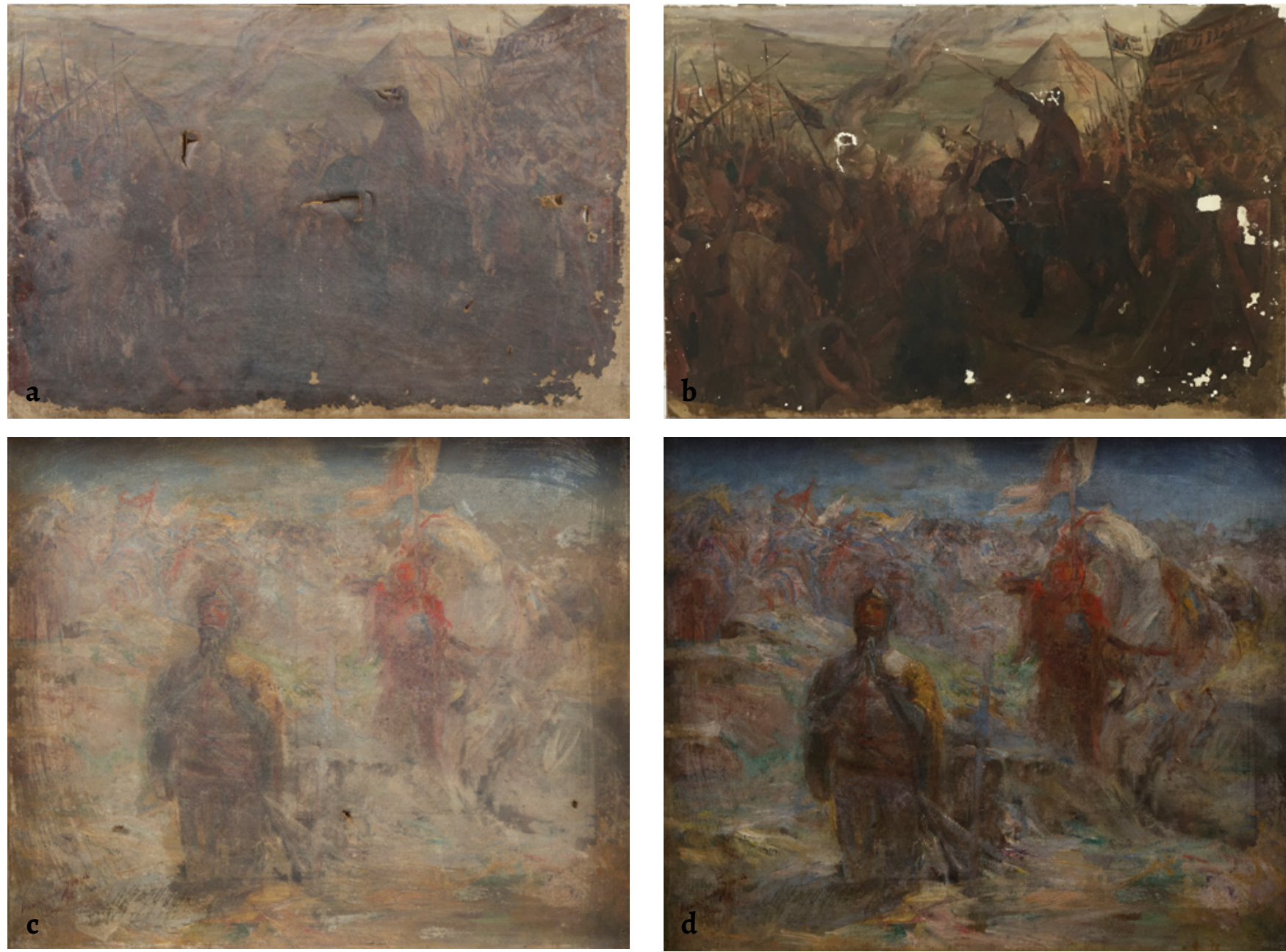

Figure 6. Painting 1 before (a) and after (b) varnishing the painting's surface. Painting 2 before (c) and after varnishing (d). 
The clean-up, in both cases, was initiated by the bottom part of the paintings moving towards the volumes. The treatment applied enabled the removal of both the layer of dirt and the film-forming layer of the aged resin. When in place, this layer delivered a painting with less saturated tones. The conservation and restoration methodology devised and put in place facilitated the reading and understanding of the two paintings by Sousa Lopes.

After hyperspectral imaging the paintings without the original varnish layer, the paintings were varnished with urea-aldehyde resin (Laropal A-81), stable to light and environmental fluctuations and removable with biodegradable and low toxicity solvents [27]. This procedure intensified the optical effect of the pictorial layer, as well as protected it from external agents (Figure 6).

\section{Hyperspectral images acquisition}

The previously described paintings were investigated using a hyperspectral imaging system, before and after the restoration cleaning.

The hyperspectral imaging system was able to acquire the reflectance spectra from the paintings with a spectral resolution of 33 spectral bands, from $400 \mathrm{~nm}$ to $720 \mathrm{~nm}$ in $10 \mathrm{~nm}$ steps. The full width at half maximum (FWHM) at $400 \mathrm{~nm}$ was of $6 \mathrm{~nm}$, at $550 \mathrm{~nm}$ of $10 \mathrm{~nm}$, and at $720 \mathrm{~nm}$ of $16 \mathrm{~nm}$. The spatial resolution of the system was of 1344 $(\mathrm{H}) \times 1024(\mathrm{~V})$ pixels with an output of 12 -bit. The system was composed of a low-noise Peltier-cooled digital camera (Hamamatsu, C4742-80-12AG, Hamamatsu Photonics K.K., Hamamatsu City, Japan) coupled to a fast-tunable liquid-crystal filter (VariSpec, model VS-VIS2-10HC35-SQ, Cambridge Research \& Instrumentation, Inc., MA), mounted in front of a zoom lens working at $75 \mathrm{~mm}$ (of a possible $12 \mathrm{~mm}$ to $75 \mathrm{~mm}$ ) and at $\mathrm{f} / 11$. An infrared filter was mounted in front of the system to prevent contamination from out-of-band transmission.

Paintings were illuminated by a discharge lamp (OSRAM HQI 150W RX7s) and any illuminant spatial nonuniformities were compensated by imaging a uniform surface in the same location and under the same illuminating conditions as the paintings. The spectral reflectance of each pixel of the paintings was estimated from a grey reference surface present near the painting. The accuracy of the system in recovering spectral reflectances of oil-painted test samples was on average within 1.3 when expressed by the CIEDE2000 colour difference equation [28]. Further details of the system can be found elsewhere [29]. Figure 7 represents the type of information that it is possible to retrieve from the hyperspectral images. Each pixel of the digital image can provide the reflectance information of the correspondent analysed area on the painting. The selected pixels on the image (a) provide the spectral reflectance from 400 to 720 $\mathrm{nm}$ in $10 \mathrm{~nm}$ steps $(b)$.

\section{Hyperspectral images processing and chromatic diversity}

The data extracted from the two paintings had about $1 \times 10^{6}$ pixels each. Each pixel had the information of the reflectance spectra and covered an area at the surface of the painting of side of about $0.73 \mathrm{~mm}$ and $0.46 \mathrm{~mm}$ for paintings 1 and 2, respectively. To better analyse the influence of the varnish layer removal, each reflectance spectrum from $400 \mathrm{~nm}$ to $720 \mathrm{~nm}$ in $10 \mathrm{~nm}$ steps was converted into a chromaticity coordinate in a colour space with visual perceptual characteristics built in. This is the CIELAB colour space where colour differences between chromaticity coordinates represent a perceptual difference assuming an observer looking at different samples with the same size under the same viewing conditions [30]. The conversion of the reflectance data into the CIELAB colour space assumed the CIE 1931 standard colorimetric observer and the CIE standard illuminant D65 [30]. Each pixel of the image was then converted into a chromaticity coordinate.

The average of the reflectance spectra was initially considered instead of individual pixel comparison as the data of the two paintings were acquired at different times in similar acquisition setups but not exactly equal, which implies that the same area of the painting before and after the varnish layer removal may not be on the same camera pixel of the correspondent acquired image, precluding the use of individual pixel comparison. To overcome this

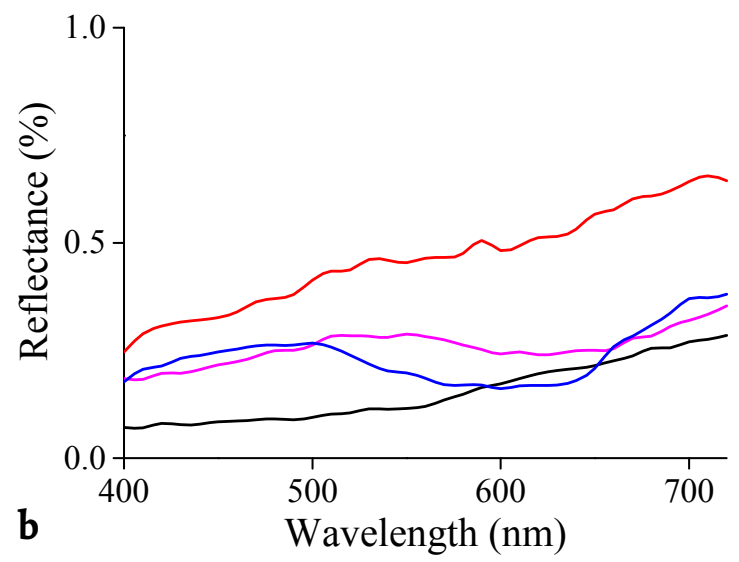

Figure 7. Reflectance spectra (b) obtained from the hyperspectral image of painting 2 in several points (a). 

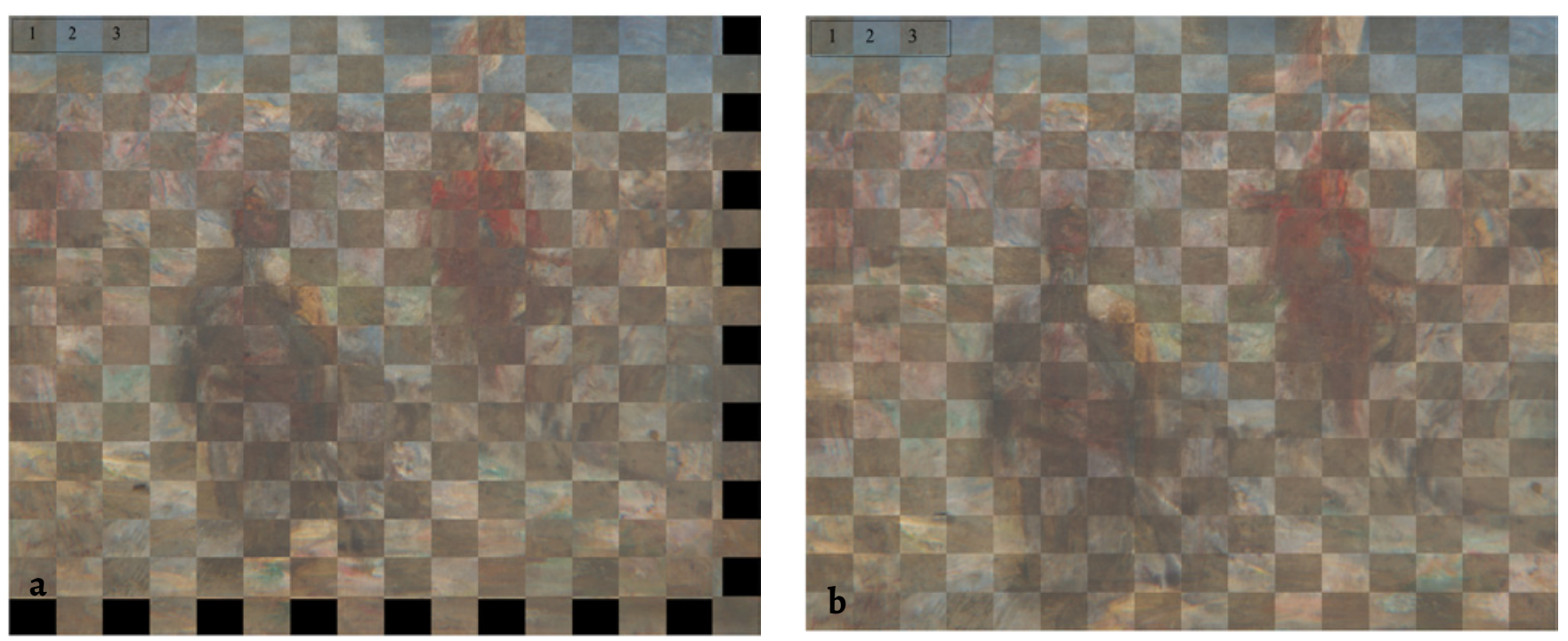

Figure 8. Images of the paintings acquired before and after the varnish layer removal, before (a) and after (b) image registration. The odd squares represent the image before the varnish layer removal and the even squares after this removal. In (a), the absence of image continuity from odd to even squares indicates that the two images are spatially different for each image pixel. After the image registration procedure (b), odd and even squares represent contiguous areas of the image, showing that both image pixels can be correlated.
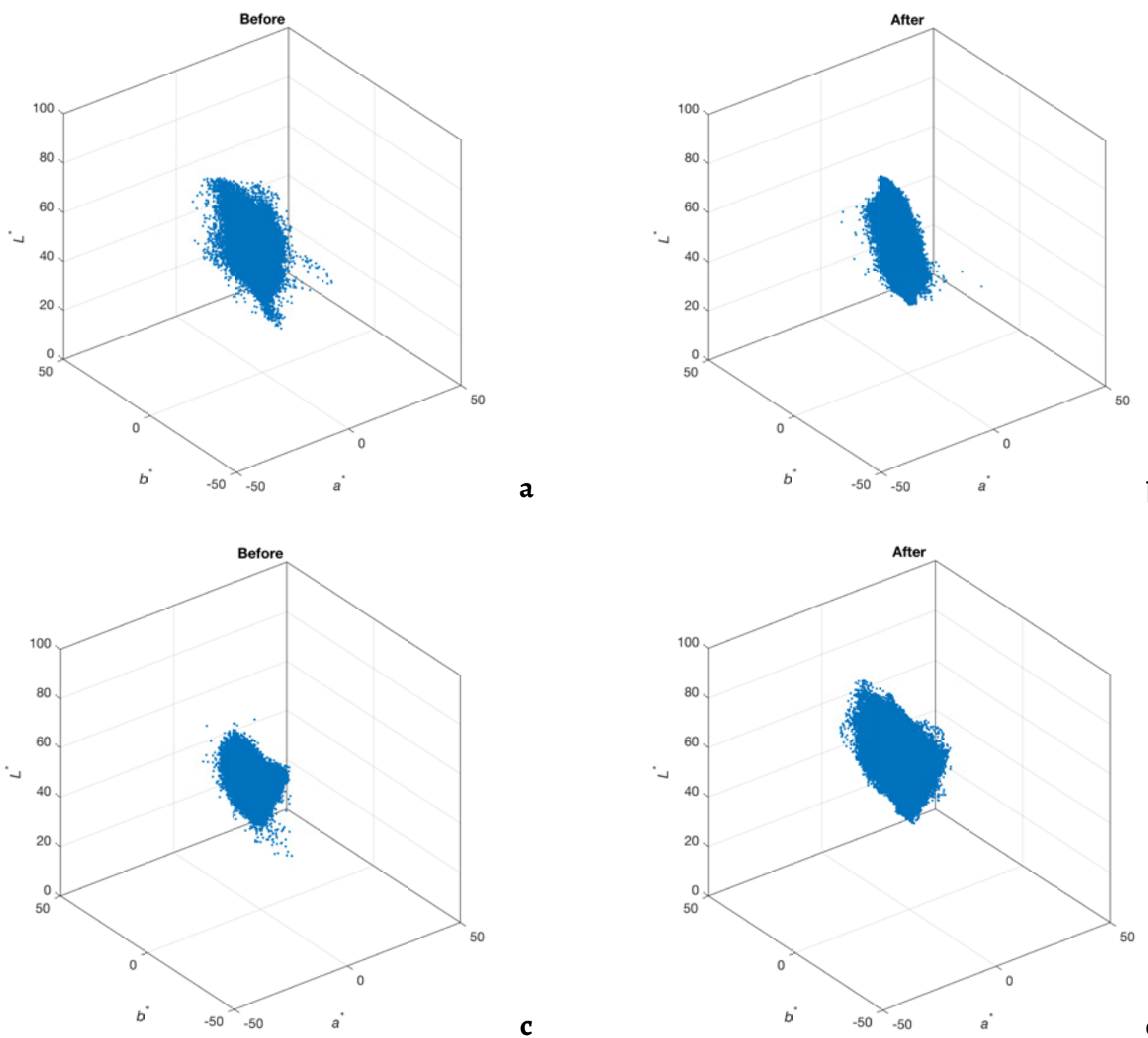

Figure 9. Representation of the image pixels in the CIELAB colour space for painting $1(a$ and $b)$ and painting $2(c$ and $d)$. Each point in the diagram is a chromaticity coordinate, estimated from the reflectance information, before the removal $(a$ and $c$ ) and after the removal $(b$ and $d$ ) of the varnish layer. Visual representations of the paintings acquired before and after the removal of the varnish layer are depicted in Figure 16. 
limitation, images were spatially registered using Matlab (MathWorks, Natick, MA, USA) in the spatial domain and the results were compared in the CIELAB domain. Figure 8 represents the effect of the image registration process.

Figure 9 represents the chromaticity coordinates in the CIELAB colour space obtained from the reflectance data of painting 1 and 2 , before and after the varnish layer removal.

To quantify the chromatic diversity on each painting and analysed condition, two metrics of chromatic diversity were used: the color gamut and the number of discernible colors. The colour gamut was estimated by computing the volume occupied by the convex hull that enclosed all the colours in the CIELAB colour space (convexHull routine, MatLab,

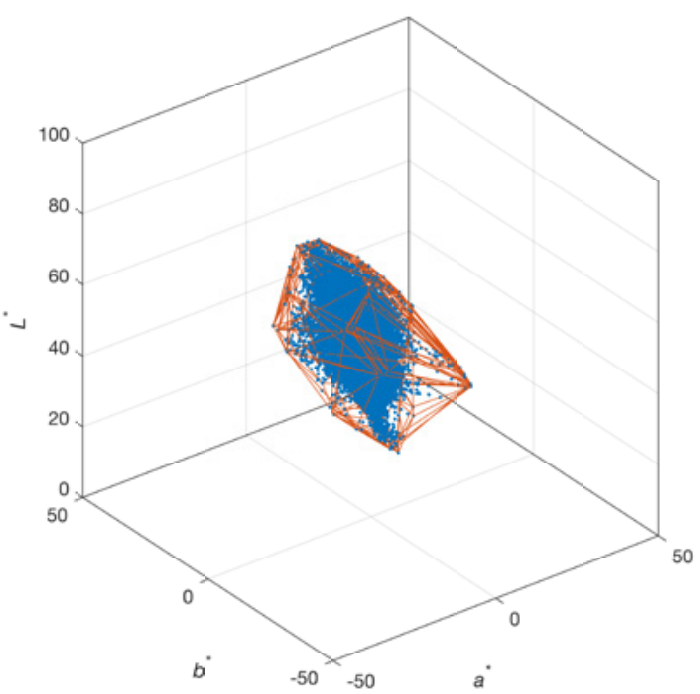

Figure 10. Representation of the convex hull (orange lines) that encloses all the colours inside (blue points). Depicted are the chromaticity coordinates of painting 1 , before the removal of the varnish layer.

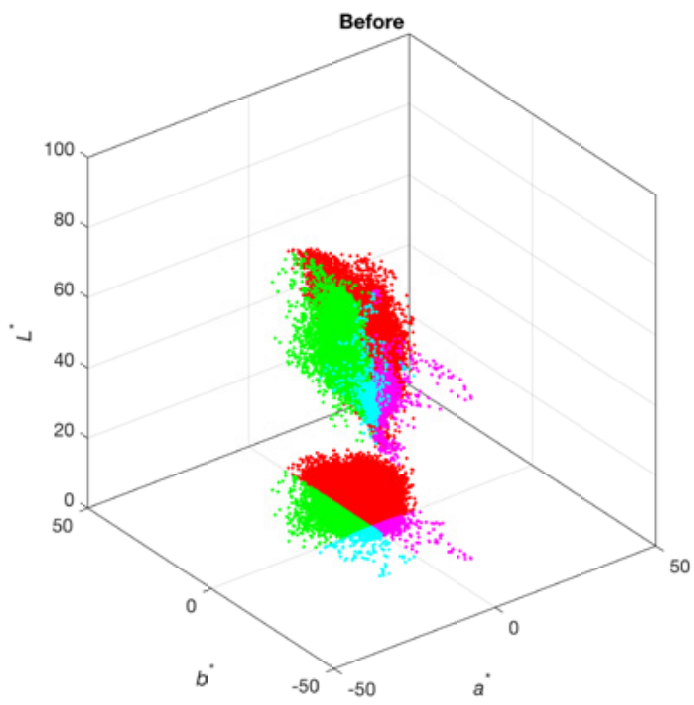

Figure 11. Representation of the segmentation of the CIELAB colour space into four quadrants, disregarding the $L^{*}$ information, on the $2 \mathrm{D}$ projection plot. The point area visible on the lower part of the figure represents the projection of the chromaticity coordinates distributed along the four quadrants (magenta, cyan, green and red for quadrant 1, 2, 3 and 4, respectively).
MathWorks, Natick, MA, USA). Figure 10 represents with orange lines, in the CIELAB colour space, the convex hull estimated to enclose all the colours of painting $I$ (represented as blue points), before the removal of the varnish layer. The volume was estimated by computing the volume occupied by the geometric form created by the convex hull (orange lines). An increasing colour gamut was assumed as an increasing chromatic content.

The number of discernible colours was also estimated to represent the chromatic diversity that an observer could perceive when observing the paintings. The number of discernible colours was estimated by segmenting the CIELAB colour volume into a cubic lattice with unitary volume in each individual cube. It was assumed that all the chromaticity coordinates that were inside the same unitary cube could not be distinguishable and were considered as one individual colour. Counting the number of non-empty cubes will provide an estimative of the number of discernible colours [19, 31]. Higher numbers of discernible colours were assumed as an increased chromatic content. The latter estimation will provide information about the chromatic diversity without considering empty volumes that can be computed using the convex hull methodology.

\section{Estimation of the influence of the removal of the varnish layer}

The data of the two paintings used in this analysis was obtained using hyperspectral imaging before and after the varnish layer removal. The reflectance spectra of the painting with and without the varnish layer were obtained and used to estimate the average overall effect of the varnish layer. If $R_{a}$ is the reflectance spectra of an area of a painting after the varnish layer removal and $R_{b}$ the reflectance spectra of the same area before the varnish layer removal, then it is possible to estimate the overall influence of the varnish layer [30] $V_{L}$ by $R_{a} \cdot V_{L}=R_{b}<=>V_{L}=R_{b} / R_{a}$, without considering the contribution of each individual layer in the elaboration of the light information that is obtained from the painting [33]. This methodology is an over simplification of the effect of a varnish layer on a coloured surface as described elsewhere [5, 13-14, 34-35]. Nevertheless, for the purpose of analysing the chromatic changes it is a rough methodology that may give fast indicative results $[15,34]$ which may be of importance when the varnish used to cover the painting is unknown or there is no physical access to the painting to retrieve a sample of the varnish.

The reflectance spectra of the painting before and after the varnish layer removal were averaged across all pixels segmented into correspondent volumes in the CIELAB colour space and used to estimate the influence of the varnish. Such correspondent volumes provided comparison among alike hues. The CIELAB colour volume was segmented into four quadrants, disregarding the $L^{*}$ information. Quadrant 1, 2, 3 and 4 was considered as $a^{*} \geq 0$ and $b^{*} \geq 0, a^{*}>0$ and $b^{*}<0, a^{*} \leq 0$ and $b^{*} \leq 0$ and $a^{*}<0$ and $b^{*}>0$, 
respectively, attaining the influence of the varnish layer in several areas of the painting correspondent to the same hue. Quadrants 1, 2, 3 and 4 are represented in magenta, cyan, green and red, respectively, in Figure 11.

The varnish layer information obtained was then used to digitally remove the varnish layer of the $R_{b}$ reflectance towards obtaining the simulated $R_{a S}$ reflectance. The differences between the acquired reflectance $R_{a}$ and the simulated reflectance $R_{a S}$ was estimated by converting the reflectance information into the CIELAB chromaticity coordinates as described previously and by computing the Euclidean distance $\triangle E$ between correspondent pixels' chromaticity coordinates in the CIELAB colour space, assuming

$$
\Delta E=\sqrt{\left(L_{a}^{*}-L_{a s}^{*}\right)^{2}+\left(a_{a}^{*}-a_{a S}^{*}\right)^{2}+\left(b_{a}^{*}-b_{a S}^{*}\right)^{2}} .
$$

\section{Results}

\section{Chromatic descriptors and variations}

Figure 9 represents the chromaticity coordinates of painting 1 and 2, represented in the CIELAB colour volume before and after the removal of the varnish layer. It is possible to see that the volume occupied by the chromaticity coordinates (the colour gamut) on painting 1 decreases while the colour gamut of painting 2 increases with the removal of the varnish layer. The averages of the chromaticity coordinates estimated in the CIELAB colour space are represented in Table 1. The average CIELAB value does not change much when considering painting 1 , but on painting 2 removing the varnish will mainly increase the average $L^{*}$. If the maximum values are considered, the $L^{*}$ increases in both paintings, of about 5 and $16 L^{*}$ units in paintings 1 and 2 , respectively.
Table 1. Average and standard deviation (STD) values of the CIELAB chromaticity coordinates of paintings 1 and 2, before and after the removal of the varnish layer.

\begin{tabular}{ccccccc}
\hline & \multicolumn{3}{c}{ Before (average \pm STD) } & \multicolumn{3}{c}{ After (average \pm STD) } \\
\hline Painting & $\boldsymbol{L}^{*}$ & $\boldsymbol{a}^{*}$ & $\boldsymbol{b}^{*}$ & $\boldsymbol{L}^{*}$ & $\boldsymbol{a}^{*}$ & $\boldsymbol{b}^{*}$ \\
\hline \multirow{2}{*}{1} & 40.5 & 3.0 & 6.0 & 40.3 & 4.2 & 7.3 \\
& \pm 5.2 & \pm 1.9 & \pm 3.4 & \pm 7.2 & \pm 2.3 & \pm 3.6 \\
& 45.7 & 2.4 & 9.6 & 54.6 & 1.8 & 8.1 \\
& \pm 3.7 & \pm 2.6 & \pm 3.2 & \pm 6.7 & \pm 4.1 & \pm 5.6 \\
\hline
\end{tabular}

The percentage variations of some chromatic descriptors and the number of image pixels involved in each computation were estimated by assuming all the CIELAB colour space or each one of its quadrants (Figure 11). In the case of the number of discernible colours or colour gamut estimations, positive values represent an increase and negative values a decrease on the represented quantity, when comparing the painting with varnish with the painting with no varnish layer. For painting 1 a decrease was found in the number of discernible colours and colour gamut estimations either assuming the complete volume or the volume projection on the $\operatorname{CIE}\left(a^{*}, b^{*}\right)$ diagram, as all data are negative. Considering all the chromaticity coordinates (first line of Table 2) the decrease in the colour volume is about $50 \%$ while the number of discernible colours only decreases about $20 \%$. For painting 2 the number of discernible colours increased by about $146 \%$ and the colour gamut increased by about $65 \%$, considering all the chromaticity coordinates. For painting 2 all the analysed variations presented an increase after removal of the varnish layer. In both cases the majority of the pixels are in quadrant 1 , with the remaining quadrants presenting very few pixels, hence the big variations when considering

Table 2. Percentage of chromatic variations with the removal of the varnish layer for paintings 1 and 2 , assuming the entire amount of available chromaticities, and the available chromaticities in each CIELAB quadrant.

\begin{tabular}{|c|c|c|c|c|c|c|c|}
\hline & \multirow{2}{*}{$\begin{array}{c}\text { Chromaticity } \\
\text { coordinates }\end{array}$} & \multicolumn{2}{|c|}{ Number of discernible colours } & \multicolumn{2}{|c|}{ Colour gamut } & \multicolumn{2}{|c|}{ Percentage of pixels used (\%) } \\
\hline & & CIELAB & $\operatorname{CIE}\left(a^{*}, b^{*}\right)$ & CIELAB & $\operatorname{CIE}\left(a^{*}, b^{*}\right)$ & Before & After \\
\hline \multirow[t]{5}{*}{ Painting 1} & All & -20.7 & -49.6 & -54.9 & -59.5 & 100 & 100 \\
\hline & $Q_{1}$ & -13.8 & -38.9 & -41.4 & -38.4 & 96.4 & 97.8 \\
\hline & $\mathrm{Q}_{2}$ & -51.4 & -60.9 & -59.5 & -67.7 & 0.5 & 0.3 \\
\hline & Q3 & -42.5 & -58.6 & -81.8 & -84.1 & 0.1 & 0.1 \\
\hline & $\mathrm{Q}_{4}$ & -30.1 & -58.8 & -58.2 & -55.2 & 3 & 1.8 \\
\hline \multirow[t]{5}{*}{ Painting 2} & All & 146.6 & 91.2 & 65.3 & 65.8 & 100 & 100 \\
\hline & $Q_{1}$ & 130.2 & 77.0 & 84.0 & 109.2 & 84.2 & 67.3 \\
\hline & $\mathrm{Q}_{2}$ & 371.5 & 173.7 & 38.8 & 34.5 & o & 0.2 \\
\hline & Q3 & 277.2 & 116.4 & 47.7 & 61.8 & 0.4 & 8.5 \\
\hline & Q4 & 130.6 & 78.9 & 56.6 & 119.2 & 15.4 & 24 \\
\hline
\end{tabular}

Notes: Data are presented for the number of discernible colours, the volume and the area estimated by convex hull (estimating the colour gamut) assuming all the dimensions of the CIELAB colour space and ignoring $L^{*}$, respectively. Negative values represent a decrease and positive values an increase in the analysed quantity. 


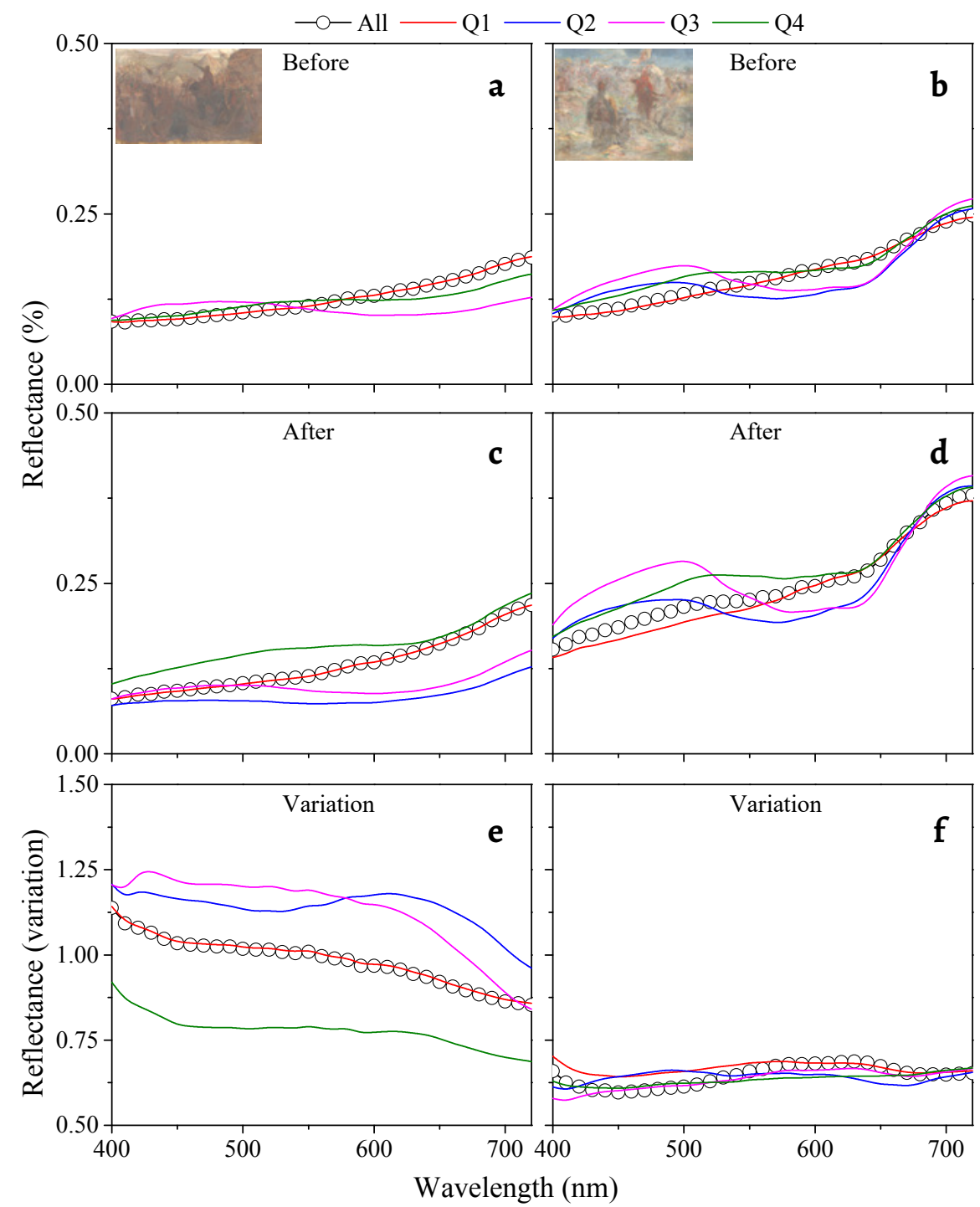

Figure 12. Reflectance data correspondent to the influence of the varnish layer: painting 1 ( $a, c$ and $e$ ) and painting 2 ( $b, d$ and $f$ ). Black line with open circles represents the average reflectance across all pixels, and the red, blue, magenta and green lines represent the average across the pixels that have colours that are represented on quadrant 1, 2, 3 and 4 of the CIELAB colour volume respectively. $a$ ) and $b$ ) represent data for before the varnish layer removal and c) and $d$ ) for after varnish layer removal. $e$ ) and f) represent the differences between them in variations of the reflectance.

the variations per quadrant that can increase up to $371 \%$ for painting 2 and quadrant 2 or a decrease of about $81 \%$ for painting 1 and quadrant 3 . Only on painting 2 the removal of the varnish layer will provide a redistribution of the number of pixels for other quadrants with some impact, but with little effect (identical variations across quadrants) on the chromatic descriptors, indicating that the number of pixels with identical colours increased.

\section{Estimating the effect of the varnish layer}

The effect of the varnish layer was estimated by computing the spectral reflectance differences between the same painting with and without the varnish layer. The estimated differences in the reflectance spectra higher than one will represent a decrease in the overall chromatic descriptors, and a difference smaller than one will represent an increase in the overall chromatic descriptors. Figure 12 represents such variations. On Figures $12 a$ and $12 b$ the average reflectance estimated across the entire number of pixels (black line with open circles) is represented for painting 1 and painting 2, still with the varnish layer serving as protective layer. Also represented in red, blue, magenta and green are the average of the reflectances for the pixels that are represented on the quadrant $1,2,3$ and 4 of the CIELAB colour space (Figure 11). Figures $12 c$ and $12 d$ represent the same data but considering paintings after the varnish layer removal. Figures $12 e$ and $12 f$ represent the estimated spectral influence of the varnish layer when computing the differences between the imagens with and without the varnish layer estimated across the entire number of pixels (black line with open circles) and for quadrant 1, 2, 3 and 4 of the CIELAB colour space (in red, blue, magenta and green, respectively).

It was found that the difference in the average reflectances between before and after the varnish removal will provide average reflectances higher than one for painting 1 and 
smaller than one for painting 2 (as represented on Figures $12 e$ and 12f), which will provide a smaller number of discernible colours and colour gamut for painting 1 and higher number of discernible colours and colour gamut for painting 2, as described in Table 2. It was found that in all cases the average across all pixels will closely follow the average of the pixels that have colours on quadrant 1 - which is not a surprise, considering the number of pixels that are represented in quadrant 1 for both paintings.

To test the influence of the averaged spectral properties of the removed varnish layer, two methodologies were used. In both the varnish layer was digitally removed and the resulting image was then compared with the painting with the varnish layer effectively removed. The digital removal of the varnish layer was done assuming the average spectral information across colours and paintings, as represented in Figure 13 with the black line and open circles (labelled as simulation 1) and assuming each varnish layer for each painting distributed into quadrants, as represented in Figures $12 e$ and $12 f$ (and labelled as simulation 2). Differences between the expected image and the simulations were estimated by computing the Euclidean distance between the expected and obtained CIELAB coordinates, and represented as a distribution of frequencies.

Figure 14 represents the results for simulation 1 (averages across colours and paintings) with red bars and for simulation 2 (averages across quadrants and paintings' own information) with black bars for paintings 1 and 2. It was found that there is a higher frequency of smaller errors for simulation 2 (black bars) for both paintings. This result indicates that simulation 2 provides fewer chromatic errors when comparing the painting and the simulation without varnish layer. As such, for the purpose of this work, only simulation 2 will be considered further on when analysing the data. The most frequent chromatic error estimated in

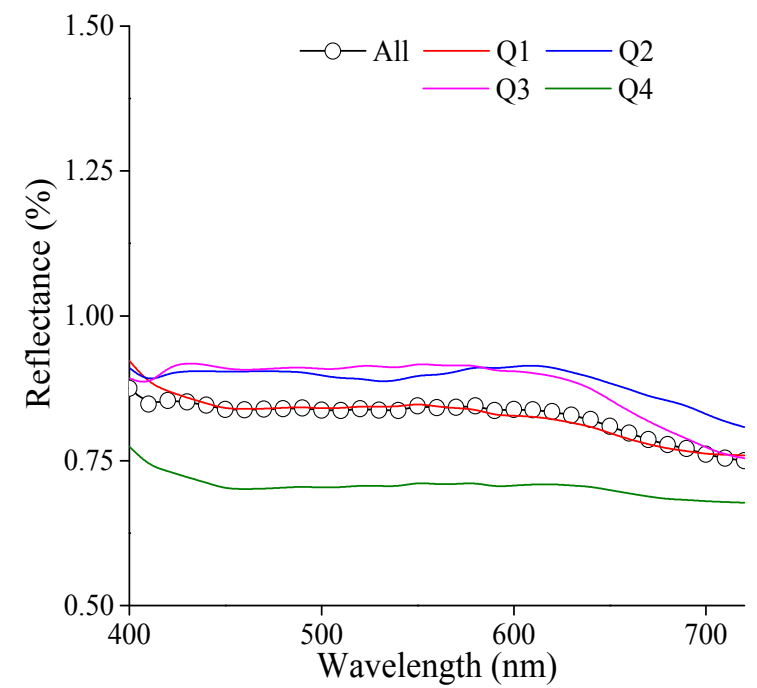

Figure 13. Average of the reflectance of the effect of the varnish layer, estimated across quadrants and paintings (red, blue, magenta and green for quadrant 1, 2, 3 and 4, respectively) and across entire set of colours and paintings (black line with open circles).

the CIELAB colour space was of 3 and $5 \Delta E$ units for paintings 1 and 2, respectively, indicating that the methodology used was more effective on painting 1. If only the chromatic error is considered, ignoring the $L^{*}$ information, the most frequent error in the $\operatorname{CIE}\left(a^{*}, b^{*}\right)$ chromaticity diagram was found to be 2 and $3 \Delta E$ units for paintings 1 and 2, respectively, as represented in Figure 15. The number of pixels involved in errors in which $\Delta E \geq 10$ is $4.6 \%$ and $12.8 \%$, for paintings 1 and 2, respectively, when estimated in CIELAB, and $1.4 \%$ and 5.6 $\%$, when estimated in $\operatorname{CIE}\left(a^{*}, b^{*}\right)$. These results suggest that the methodology used is better at predicting the chromatic changes rather than predicting lightness.

Table 3 represents the average CIELAB values for the simulated paintings without the varnish layer, assuming the removal of varnish effect estimated using each painting's

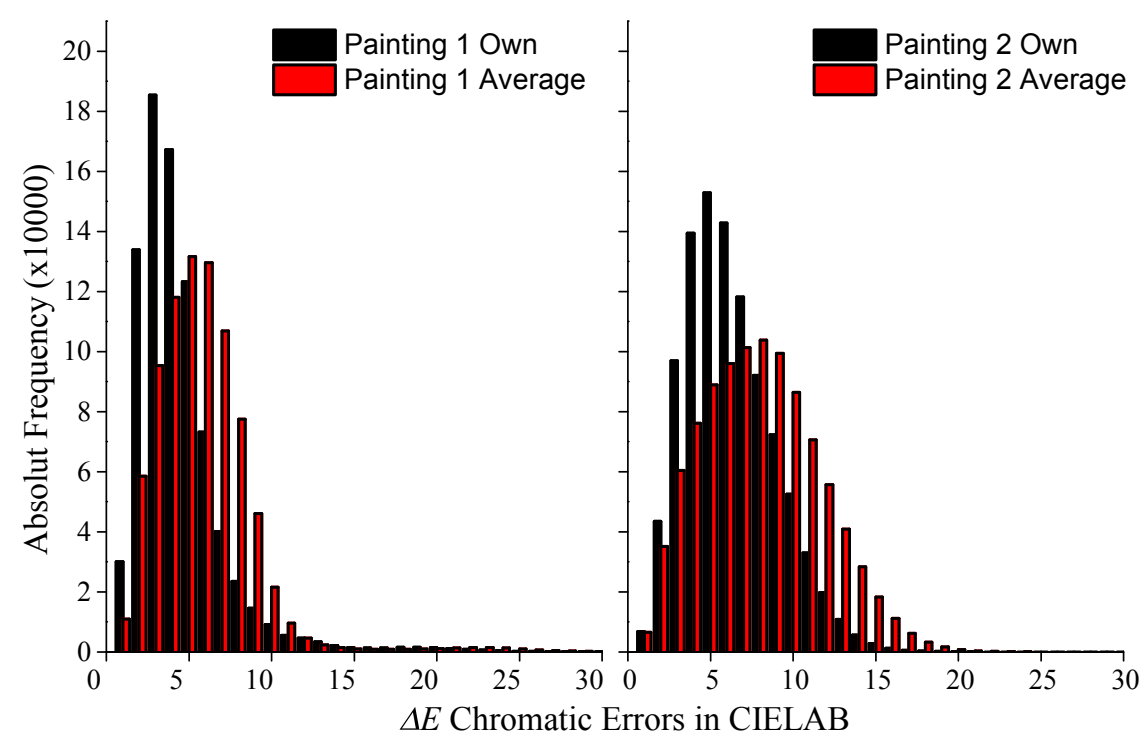

Figure 14. Representation of the error frequency in CIELAB when comparing the real painting with the simulated one, assuming the information of the varnish layer averaged across colours and paintings (simulation 1, red bars) and across quadrants using the painting' own information (simulation 2 , black bars), for painting 1 (a) and painting 2 (b). 
varnish layer information averaged across the four quadrants (simulation 2). It was found that the average CIELAB values obtained from simulation 2 are not much different from the ones obtained after the measurement of the painting without the varnish layer and represented on the right side of Table 1. Nevertheless, when further chromatic descriptors are used, it is visible that the simulation does not quite agree with the expected final result of removing the varnish layer. Table 4 represents the percentage variations of these chromatic estimators, namely the number of discernible colours and the colour gamut and the number of pixels of the total image used in each estimation. As in Table 2, positive numbers represent an increase and negative values a decrease of the analysed quantity. It was found that for painting 1 the simulated number of discernible colours and colour gamut is greater than the real one, which represents an overestimation of the chromatic content, while for painting 2 the same chromatic descriptors are lesser than the real ones, which represents an underestimation of the chromatic content. For paining 2 it was found that the colour gamut of quadrant 2 and 3 was overestimated, but considering the number of pixels of the image involved such outcome can be overlooked. The same criteria can be applied to painting 1 and the huge overestimation of the colour gamut of quadrant 3 and 4 of about $326 \%$ and $180 \%$, respectively, as the number of pixels involved is, again, small.

Figure 16 represents visual simulations of the results obtained when applying the virtual removal of the varnish layer using simulations 1 and 2. On Figures $16 a$ and 16b, and $16 c$ and $16 d$ are represented, for comparison, the paintings with and without the varnish layer, respectively.
Table 3. Average and standard deviation (STD) values of the CIELAB chromaticity coordinates of paintings 1 and 2 , after the simulation of the removal of the varnish layer - simulation 2 .

\begin{tabular}{cccc}
\hline \multicolumn{4}{c}{ Simulation (average \pm STD) } \\
\hline Painting & $\boldsymbol{L}^{*}$ & $\boldsymbol{a}^{*}$ & $\boldsymbol{b}^{*}$ \\
\hline 1 & $40.7 \pm 5.4$ & $4 \pm 2$ & $7.4 \pm 3.5$ \\
\hline 2 & $54.5 \pm 4.4$ & $2.8 \pm 3.1$ & $9.4 \pm 3.6$ \\
\hline
\end{tabular}

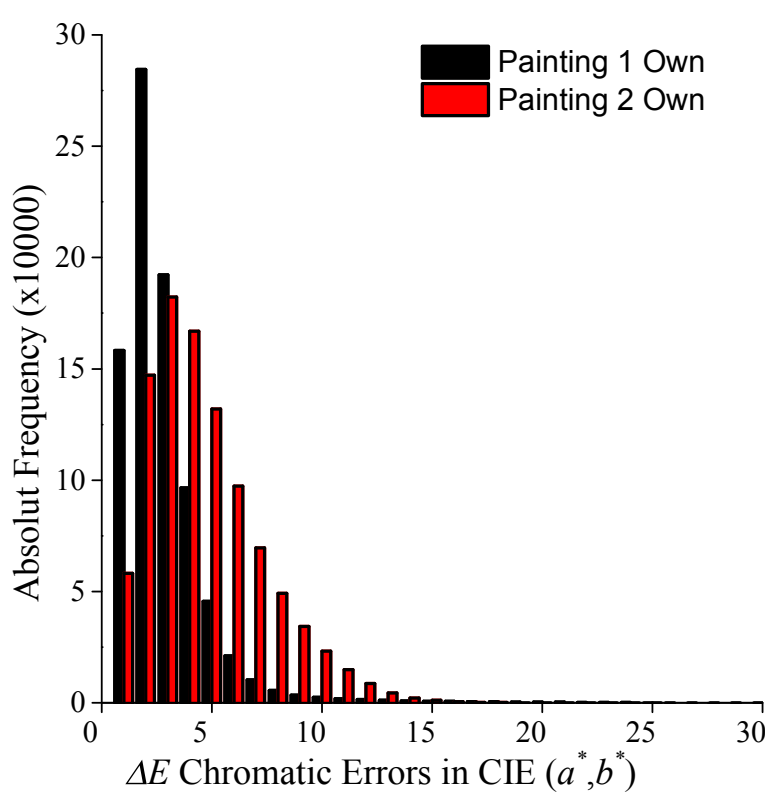

Figure 15. Representation of the error frequency in $\operatorname{CIE}\left(a^{*}, b^{*}\right)$ when comparing the real painting with the simulated one, assuming the information of the varnish layer averaged across quadrants using the painting's information (simulation 2), for painting 1 (black bars) and painting 2 (red bars).

Table 4. Percentage of chromatic variations with the simulation of the removal of the varnish layer for paintings 1 and 2 , assuming the entire amount of chromaticities available, and the chromaticities available in each CIELAB quadrant.

\begin{tabular}{|c|c|c|c|c|c|c|}
\hline & \multirow{2}{*}{$\begin{array}{l}\text { Chromaticity } \\
\text { coordinates }\end{array}$} & \multicolumn{2}{|c|}{ Number of discernible colours } & \multicolumn{2}{|c|}{ Colour gamut } & \multirow{2}{*}{$\begin{array}{c}\begin{array}{c}\text { Percentage of pixels } \\
\text { used (\%) }\end{array} \\
\text { Before } \\
\end{array}$} \\
\hline & & CIELAB & $\operatorname{CIE}\left(a^{*}, b^{*}\right)$ & CIELAB & $\operatorname{CIE}\left(a^{*}, b^{*}\right)$ & \\
\hline \multirow[t]{5}{*}{ Painting 1} & All & 33.1 & 109.0 & 128.2 & 172.7 & 100 \\
\hline & $Q_{1}$ & 26.2 & 78.0 & 89.0 & 86.3 & 97.2 \\
\hline & Q2 & 56.5 & 113.3 & 113.5 & 144.1 & 0.3 \\
\hline & Q3 & 27.3 & 93.5 & 326.6 & 356.9 & 0.1 \\
\hline & Q4 & 58.8 & 176.1 & 179.5 & 189.1 & 2.4 \\
\hline \multirow[t]{5}{*}{ Painting 2} & All & -42.3 & -31.7 & -19.1 & -4.9 & 100 \\
\hline & $Q_{1}$ & -41.1 & -30.2 & -33.1 & -30.1 & 84.1 \\
\hline & Q2 & -52.5 & -47.1 & 15.4 & 39.0 & 0.1 \\
\hline & Q3 & -49.1 & -24.1 & 13.8 & 30.2 & 0.9 \\
\hline & $Q_{4}$ & -43.9 & -34.8 & -19.9 & -31.4 & 14.9 \\
\hline
\end{tabular}

Notes: Data are presented for the number of discernible colours, the volume and the area estimated by convex hull (estimating the colour gamut) assuming all the dimensions of the CIELAB colour space and ignoring $L^{*}$, respectively. Negative values represent a decrease and positive values an increase in the analysed quantity. 
Chromatic changes in paintings of Adriano de Sousa Lopes after the removal of aged varnish
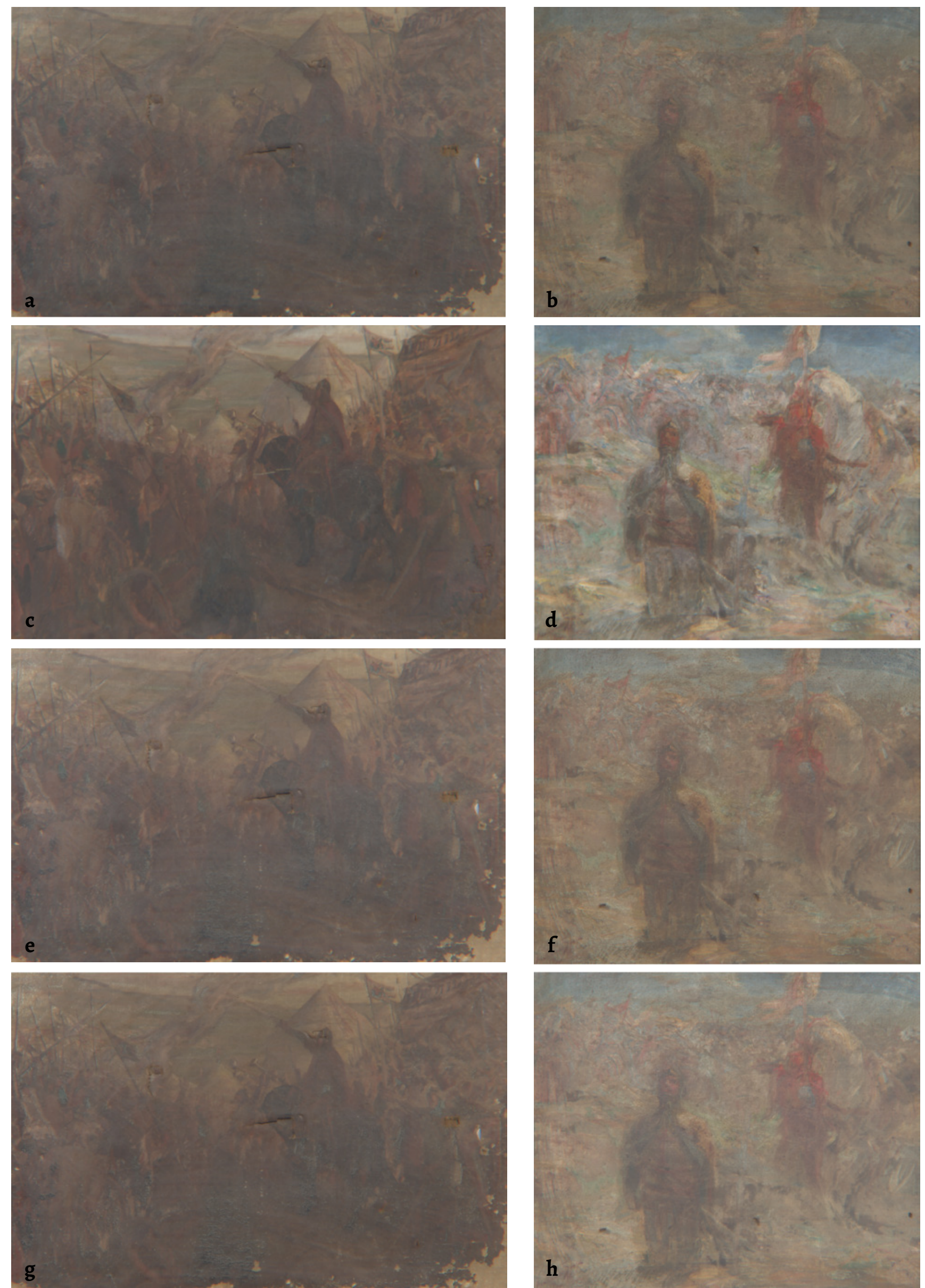

Figure 16. Visual representations of painting $1(a, c, e$ and $g)$ and painting $2(b, d, f$ and $h)$ before the varnish layer removal $(a$ and $b)$, after the varnish layer removal $(c$ and $d$ ) and simulated for the removal of the varnish layer for simulation $1(e$ and $f$ ) and simulation $2(g$ and $h)$. 


\section{Discussion and Conclusion}

Former methodologies described the digital restoration of artistic paintings, either based on spectral information [5-6] or colour information with input from spectral data [7-8] or without [10-11]. Nevertheless, the presented methods, although more representative of the optical effects in place since the light cast on the painting and is reflected and viewed or acquired [12-13, 15-16, 35], either require the knowledge of the transmittance spectra of the varnish used as a protective layer, or intend to simulate the cleaning and posterior reposition of the varnish layer.

The method proposed here is based on the comparison of the reflectance spectra of hyperspectral images from $400 \mathrm{~nm}$ to $720 \mathrm{~nm}$ in $10 \mathrm{~nm}$ steps of two artistic paintings from Adriano de Sousa Lopes acquired with and without the original aged protective varnish layer.

The purpose of such comparison disregarding the more complex and complete optical simulations is to provide a fast and comprehensive tool to simulate the effect of the aged varnish layer on the painting perception, assuming no previous knowledge of the varnish layer. Assuming no previous knowledge of the varnish layer is important as it may be composed of aged yellowish varnish, layers of dirt and dust and non uniform overlays, not only an uniform layer of transparent varnish.

The use of the spectral properties of the painting's varnish layer will provide lower chromatic errors estimated in the CIELAB colour space, when comparing the painting before and after the varnish layer removal. Using an average spectral influence of the varnish layer will produce poorer results, although in both cases the errors created are higher than the detection threshold estimated for complex images of $\Delta \mathrm{E}=2.2$ in the CIELAB colour space [36]. If only the chromatic differences are considered and lightness is ignored, the existing errors are smaller, which seems to indicate that the methodology here used is better at predicting chromatic changes rather than lightness changes.

The methodology here described was tested only over the visible range of the spectrum, excluding the assessment of the impact of the ultraviolet and infrared radiation. The colour space and colour difference formula used is also known for its non-uniformities [28]. The light source in use to light artistic painting has a strong impact on the perceived colour [19, 21]. On this work only the CIE D65 illuminant was considered leaving the impact of using other illuminants or unknown light sources. It was also assumed that the white reference was outside of the painting under analysis. Nevertheless, since the errors were compared intra and not inter paintings the non-uniformities are minimized, and the use of such colour space and colour difference formula are an advantage due to their simplicity and wide use [30].

The use of the number of discernible colours and colour gamut as chromatic descriptors were proved valuable as presenting the average CIELAB colour coordinates of the paintings' chromatic content before and after the varnish layer removal was not enough, as these data were found to be almost the same, while the chromatic descriptors were not. Dividing the CIELAB colour space into quadrants and performing the analysis using the information separated accordingly did not provide better results. It was used nevertheless, as it enables estimations and comparisons of the colours that changed quadrants with the removal of the varnish layer.

Despite the limitation of this study, the presented findings seem to indicate that the chromaticities of the paintings can be digitally estimated as if seen without the protective aged varnish layer, but further analysis is necessary to improve the digital removal of the varnish layer.

\section{Acknowledgments}

Thanks to the Foundation for Science and Technology through the HERITAS doctoral program (REF.a: PD/00297/2013), (co-financed by the European Social Fund through the Operational Programs for the 20142020 programming period of Portugal 2020), by the financing of the scholarship of Liliana Cardeira (PD/BD/128381/2017).

\section{REFERENCES}

1. Vicente, J. P., 'Estudio analítico de materiales empleados en barnices, aglutinantes y consolidantes en obras de arte mediante métodos cromatográficos y esctrométricos', $\mathrm{PhD}$ dissertation, Universitat de València, València (2007), http:// roderic.uv.es/handle/10550/15821.

2. Ortiz, A. S., Restauración de Obras de Arte: Pintura de Caballete, Ediciones AKAL, Madrid (2002).

3. Nicolaus, K., Manual de Restauración de Cuadros, Könemann, Köln (1999).

4. 'E.C.C.O - Professional Guidelines II. Code of ethics', http:// www.ecco-eu.org/documents/ (accessed 2019-6-10).

5. Trumpy, G.; Conover, D.; Simonot, L.; Thoury, M.; Picollo, M.; Delaney, J. K., 'Experimental study on merits of virtual cleaning of paintings with aged varnish', Optics Express 23(26) (2015) 33836-33848, https://doi.org/10.1364/OE.23.033836.

6. Elias, M.; Cotte, P., 'Multispectral camera and radiative transfer equation used to depict Leonardo's sfumato in Mona Lisa', Applied Optics 47(12) (2008) 2146-2154, https://doi. org/10.1364/AO.47.002146.

7. Berns, R. S.; Byrns; S.; Casadio, F.; Fiedler, I.; Gallagher, C.; Imai, F. H.; Newman, A.; Taplin, L. A., 'Rejuvenating the color palette of Georges Seurat's A Sunday on La Grande Jatte 1884: A simulation', Color Research Application 31(4) (2006) 278293, https://doi.org/10.1002/col.20223.

8. Berns, R. S., 'Rejuvenating the appearance of cultural heritage using color and imaging science techniques', in AIC Colour 2005. Proceedings of the 10th Congress of the International Colour Association, ed. J. L. Nieves \& J. Hernández-Andrés, International Colour Association (2005) 369-374.

9. Berns, R. S.; Rie, E. R. de la, 'The effect of the refractive index of a varnish on the appearance of oil paintings', Studies in Conservation 48(4) (2003) 251-262, https://doi.org/10.1179/ sic.2003.48.4.251.

10. Barni, M.; Bartolini, F.; Cappellini, V., 'Image processing for virtual restoration of artworks', IEEE Multimedia 7(2) (2000) 34-37, https://doi.org/10.1109/93.848424. 
11. Pappas, M.; Pitas, I., 'Digital color restoration of old paintings', IEEE Transaction on Image Processing 9(2) (2000) 291294, https://doi.org/10.1109/83.821745.

12. Faul, F.; Ekroll, V., 'Psychophysical model of chromatic perceptual transparency based on substractive color mixture', Journal of the Optical Society of America A 19(6) (2002) 1084-1095, https://doi.org/10.1364/JOSAA.19.001084.

13. Simonot, L., 'Photometric model of diffuse surfaces described as a distribution of interfaced Lambertian facets', Applied Optics 48(30) (2009) 57-93, https://doi.org/10.1364/ AO.48.005793.

14. Elias, M.; Simonot, L.; Menu, M., 'Bidirectional reflectance of a diffuse background covered by a partly absorbing layer', Optics Communication 191(1-2) (2001) 1-7, https://doi.org/10.1016/ S0030-4018(01)01087-2.

15. Simonot, L.; Elias, M., 'Color change due to a varnish layer', Color Research Application 29(3) (2004) 196-204, https://doi. org/10.1002/col.20008.

16. Rie, E. R. de la, 'The influence of varnishes on the appearance of paintings', Studies in Conservation 32(1) (1987) 1-13, https:// doi.org/10.1179/sic.1987.32.1.1.

17. Cosentino, A., 'Multispectral imaging system using 12 interference filters for mapping pigments', Conservar Património 21(1) (2015) 25-38, https://doi.org/10.14568/ cp2015005.

18. Cotte, P.; Dupraz, D., 'Spectral imaging of Leonardo Da Vinci's Mona Lisa: A true color smile without the influence of aged varnish', Color Graphics Imaging and Vision 3 (2006) 311-317.

19. Linhares, J. M. M.; Pinto, P. D. A.; Nascimento, S. M. C., 'Color rendering of art paintings under CIE illuminants for normal and color deficient observers', Journal of the Optical Society of America 26(7) (2009) 16-68, https://doi.org/10.1364/ JOSAA.26.001668.

20. Nascimento, S. M. C.; Linhares, J. M. M.; Montagner, C.; João, C. A. R.; Amano, K.; Alfaro, C.; Bailão, A., 'The colors of paintings and viewers' preferences', Vision Research 130 (2017) 76-84, https://doi.org/10.1016/j.visres.2016.11.006.

21. Pinto, P. D.; Linhares, J. M. M.; Nascimento, S. M. C., 'Correlated color temperature preferred by observers for illumination of artistic paintings', Journal of the Optical Society of America A 25(3) (2008) 623-630, https://doi.org/10.1364/ JOSAA.25.000623.

22. Cardeira, L.; Bailão, A. (ed.), Adriano de Sousa Lopes. Conservação e Restauro das Obras Académicas Pertencentes ao Espólio da Faculdade de Belas Artes da Universidade de Lisboa, CIEBA, Lisboa (2018).

23. Phenix, A., Solvent abuse: Some observations on the safe use of solvents in the cleaning of painted and decorated surfaces. The building conservation directory, Cathedral Communications, London (1997).

24. Murcia, L., "Reemplazo de solventes tóxicos: Una propuesta práctica para los talleres de restauración de nuestro país.", in Jornada de Técnicas de Reparación y Conservación del Patrimonio; IV Congreso Iberoamericano y XII Jornada de Técnicas de Reparación y Conservación del Patrimonio, ed Laboratorio de Entrenamiento Multidisciplinario para la Investigación Tecnológica (LEMIT), La Plata, Argentina (2015) 421-429, http://digital.cic.gba.gob.ar/handle/11746/1369 (Accessed at 2019-06-24).
25. Barros, J. M., 'Sistema de limpieza desarrollados por Richard Wolbers', in Seminario sobre la limpieza de pinturas de caballete, ed. V. Ramón, J. Barros \& M. Poveda, Editorial Universidade Politécnica de Valência, Valencia, 62-65.

26. Wolbers, R., Cleaning Painted Surfaces. Aqueous Methods, Archetype Publications, London (2000).

27. Arslanoglu, J.; Learner, T., 'The evaluation of Laropal A81: Paraloid B-72 polymer blend varnishes for painted and decorative surfaces - appearance and practical considerations', The Conservator 25(1) (2001) 62-72, https://doi. org/10.1080/01410096.2001.9995165.

28. Luo, M. R.; G. Cui, G.; Rigg, B., 'The development of the CIE 2000 colour-difference formula: CIEDE2000', Color Research Application 26(5) (2001) 340-350, https://doi.org/10.1002/ col.1049.

29. Pinto, P. D.; Linhares, J. M. M.; Carvalhal, J. A.; Nascimento, S. M. C., 'Psychophysical estimation of the best illumination for appreciation of Renaissance paintings', Visual Neuroscience 23(3-4) (2006) 669-674, https://doi.org/10.1017/ So952523806233340.

30. Carter, E. C.; Ohno, Y.; Pointer, M. R.; Robertson, A. R.; Sève, R.; Schanda, J. D.; Witt, K., Colorimetry, 15:2004, 3th ed., Commission Internationale de l'Éclairage, Viena (2004).

31. Pointer, M. R.; Attridge, G. G., 'The number of discernible colours', Color Research Application 23(1) (1998) 52-54, https://doi.org/10.1002/ (SICI)1520-6378(199802)23:1<52::AID-COL8>3.0.CO;2-2.

32. Palomero, C. M. T.; Soriano, M. N., 'Digital cleaning and "dirt" layer visualization of an oil painting', Optical Express 19(21) (2011) 21011-21017, https://doi.org/10.1364/OE.19.021011.

33. Kubelka, P., 'New Contributions to the optics of intensely light-scattering materials part II: nonhomogeneous layers', Journal of the Optical Society of America A 44(4) (1954) 330-335, https://doi.org/10.1364/JOSA.44.000330.

34. Saunderson, J. L., 'Calculation of the Color of Pigmented Plastics', Journal of the Optical Society of America A 32(12) (1942) 727-736, https://doi.org/10.1364/JOSA.32.000727.

35. Elias M.; Simonot, L.; Thoury, M.; Frigerio, J. M., 'Bi-directional reflectance of a varnished painting', Optics Communication 231(1-6) (2004) 25-33, https://doi.org/10.1016/j. optcom.2003.12.008.

36. Aldaba, M. A.; Linhares, J. M. M.; Pinto, P. D.; Nascimento, S. M. C.; Amano, K.; Foster, D. H., 'Visual sensitivity to color errors in images of natural scenes', Visual Neuroscience 23(3-4) (2006) 555-559, https://doi.org/10.1017/S0952523806233467.

RECEIVED: 2018.12 .8

REVISED: 2019.4 .8

ACCEPTED: 2019.4.29

ONLINE: 2020.7.31

\section{(c) (1) (3) $(-$}

This work is licensed under the Creative Commons Attribution-NonCommercial-NoDerivatives 4.0 International License. To view a copy of this license, visit http://creativecommons.org/licenses/by-nc-nd/4.o/deed.en. 